\title{
Primary extra-uterine and extra-ovarian mullerian adenosarcoma: case report and literature review
}

Vincenzo Dario Mandato ${ }^{1 *}$, Federica Torricelli ${ }^{2}$, Valentina Mastrofilippo ${ }^{3}$, Riccardo Valli ${ }^{4}$, Lorenzo Aguzzoli ${ }^{3}$ and Giovanni Battista La Sala ${ }^{1,5}$

\begin{abstract}
Background: Extra-uterine mullerian adenosarcomas have varying biological behaviours depending on the presence of endometriosis or sarcomatous overgrowth. These behaviours manifest according to the tumours' histological characteristics and sites of origin. The best treatment and oncologic outcome have not been clarified because only a few cases of extra-uterine and extra-ovarian adenosarcoma have been described in the literature. Here, we report a case of primary peritoneal adenosarcoma with sarcomatous overgrowth and review all reported cases of adenosarcomas arising outside of the uterus and outside the ovaries to identify the best treatment options and clarify outcomes.
\end{abstract}

Case presentation: A 79-year-old woman was referred to our Department with an abdominal mass resembling a fibroid with a haemorrhage. Her gynaecological history was negative. A transvaginal and transabdominal ultrasound examination revealed a multicystic mass resembling an ovarian tumour arising from the pelvis and extending up to the abdomen. At laparotomy a peritoneal mass arising from Douglas peritoneum was resected. The uterus and adnexa appeared normal, and a supra-cervical hysterectomy with bilateral salpingo-oophorectomy was performed. No macroscopic residual disease was present. Final pathology diagnosed a malignant peripheral nerve sheath tumors with divergent differentiation. Four weeks later a new, multicystic mass was found. Due to the progressive poor condition, the patient died four months after diagnosis. Histological slides were reviewed by external expert pathologists and the final diagnosis was of extra-genital adenosarcoma with sarcomatous overgrowth. Furthermore, we also collected and analysed articles written in English regarding extra-uterine and extra-ovarian adenosarcomas published between January 1974 and October 2016. PubMed was used as a database for this search. Clinical and pathological characteristics, treatments and outcomes were assessed.

Conclusions: Only 41 cases has been reported in literature. Previous endometriosis and sarcomatous overgrowth showed an inverse effect on prognosis. Endometriosis was confirmed to have a positive effect on disease free survival Complete surgical resection is the mainstay of treatment. A worldwide registry is urgently required to collect data to standardize treatment and to obtain reliable data on prognosis.

Keywords: Mullerian extra-uterine adenosarcoma, Mullerian extra-genital adenosarcoma, Survival, Vaginal adenosarcoma, Symptoms, Treatment, Review

\footnotetext{
* Correspondence: dariomandato@gmail.com

'Unit of Obstetrics and Gynecology, IRCCS- Azienda Unità Sanitaria Locale,

Viale Risorgimento n 80, Reggio Emilia, Italy

Full list of author information is available at the end of the article
} 


\section{Background}

Mullerian adenosarcoma (AS) is a rare mesenchymal and epithelial neoplasm of low malignant potential typically occurring in the uterine corpus in perimenopausal or postmenopausal women [1]. It is a mixed tumour that usually arises as a solitary lesion with a benign but sometimes atypical glandular epithelium and low-grade sarcoma, usually of the endometrial stromal type [2].

The first case of AS was described in early 1974 by Clement and Scully [3]. AS typically arises from the corpus uterus, rarely from the cervix or ovary, and extremely rarely from the vagina or from extra-genital sites such as the peritoneum, retroperitoneum, bladder, liver or colon (Table 1) [4-39].

Generally, uterine AS presents clinically indolent behaviour, whereas AS with sarcomatous overgrowth is extremely aggressive [31] and is characterized by recurrence and metastasis at an early stage [40, 41]. Sarcomatous overgrowth is characterized by the presence of a high-grade sarcomatous component in at least $25 \%$ of the tumour [42].

A recent national cancer database study reported survival data from 2205 women with AS arising from the corpus uterus, cervix and ovary, but no consistent data regarding vaginal or extra-genital AS are available because these are extremely rare sites for AS [43]. Uterine AS is the rarest form of uterine sarcomas representing only $\sim 0.2 \%$ of all uterine malignancies. It has an age-adjusted incidence of 2 per 1000,000 for Caucasians, 3 per 1000,000 for African Americans, and 1 per 1000,000 for other ethnic groups in the US population [44, 45].

Extra-genital AS is so rare that it has not been possible to develop clear guidelines regarding treatment and prognosis [35].

Here, we reported a case of primary peritoneal AS with sarcomatous overgrowth but no associated endometriosis and reviewed all cases of AS arising outside of the uterus and outside of the ovaries published since 1974 to identify the best treatment options and clarify outcomes.

\section{Methods}

We report the clinical data, preoperative imaging, pathological findings and follow-up data for a case of primary peritoneal AS with sarcomatous overgrowth. We also performed a systematic review of the literature to collect reports on AS arising outside of the uterus and outside of the ovaries. With the term "uterus" we mean the whole organ without distinction between uterine corpus and cervix. We mean with the term "extra-uterine" all AS arising outside of the uterine corpus or of the cervix.

\section{Systematic review of the literature}

We collected and analysed articles published on AS between January 1974 and October 2016 using PubMed as a database and the following search terms: "peritoneal mullerian adenosarcoma", "primitive peritoneal mullerian adenosarcoma", "primary peritoneal mullerian adenosarcoma", "extra-uterine mullerian adenosarcoma", "primitive extra-uterine mullerian adenosarcoma", "primary extrauterine mullerian adenosarcoma", "extra-uterine mesodermal adenosarcoma", "primitive extra-uterine mesodermal adenosarcoma", "primary extra-uterine mesodermal adenosarcoma", "primary extra-genital adenosarcoma", "primitive extra-genital adenosarcoma", "primary extra-genital mullerian adenosarcoma", and "primitive extra-genital mullerian adenosarcoma". After selecting for cases arising outside of the uterus and outside the ovaries, 32 reports of extragenital AS and 9 of vaginal AS were found and included in this systematic review For each case the following data were extracted and collected in a database: age, tumor size, tumor site, previous diagnosis of endometriosis, sarcomatous overgrowth, heterologous sarcomatous differentiation therapy, presence of recurrences, recurrence site, treatment after recurrence and follow up status and time. All dichotomic parameters were codified as 0 (absent) or 1 (present), while for all cases age was reported in years, follow up was reported in months and tumor size was reported in centimetres. When a patient experienced more than one recurrence all events were reported. Missing data were indicated as not reported (NR) in database.

\section{Statistical analysis}

Statistical analysis was performed using R-3.2.3 software. Associations between clinical and pathological parameters in different subgroups of patients were assessed using linear models and Fisher's exact test.

Overall survival (OS) was computed as the time period from the date of surgery to either the date of death or last follow-up. Disease-free survival (DFS) was computed as the disease-free period from the date of surgery to the date of relapse or last follow-up. Survival curves were plotted using the Kaplan-Meier method and differences between curves were assessed by Log-Rank test.

Test were considered statistically significant with a $\mathrm{P}$ value lower than 0.05 .

\section{Case presentation}

A 79-year-old woman was referred to the Department of Obstetrics and Gynecology with an abdominal mass discovered on a computed tomography scan (CT) performed following right iliac artery angioplasty. The scan revealed a $16 \times 11 \mathrm{~cm}$ mass resembling a fibroid with a haemorrhage (Fig. 1).

Her history included type 2 diabetes, hypertension, hypercholesterolemia, glaucoma, hypothyroidism, and stage III chronic obstructive arteriopathy of the right leg, and she underwent a left carotid thromboendarterectomy 1 year prior to admission. Her gynaecological history was negative. 


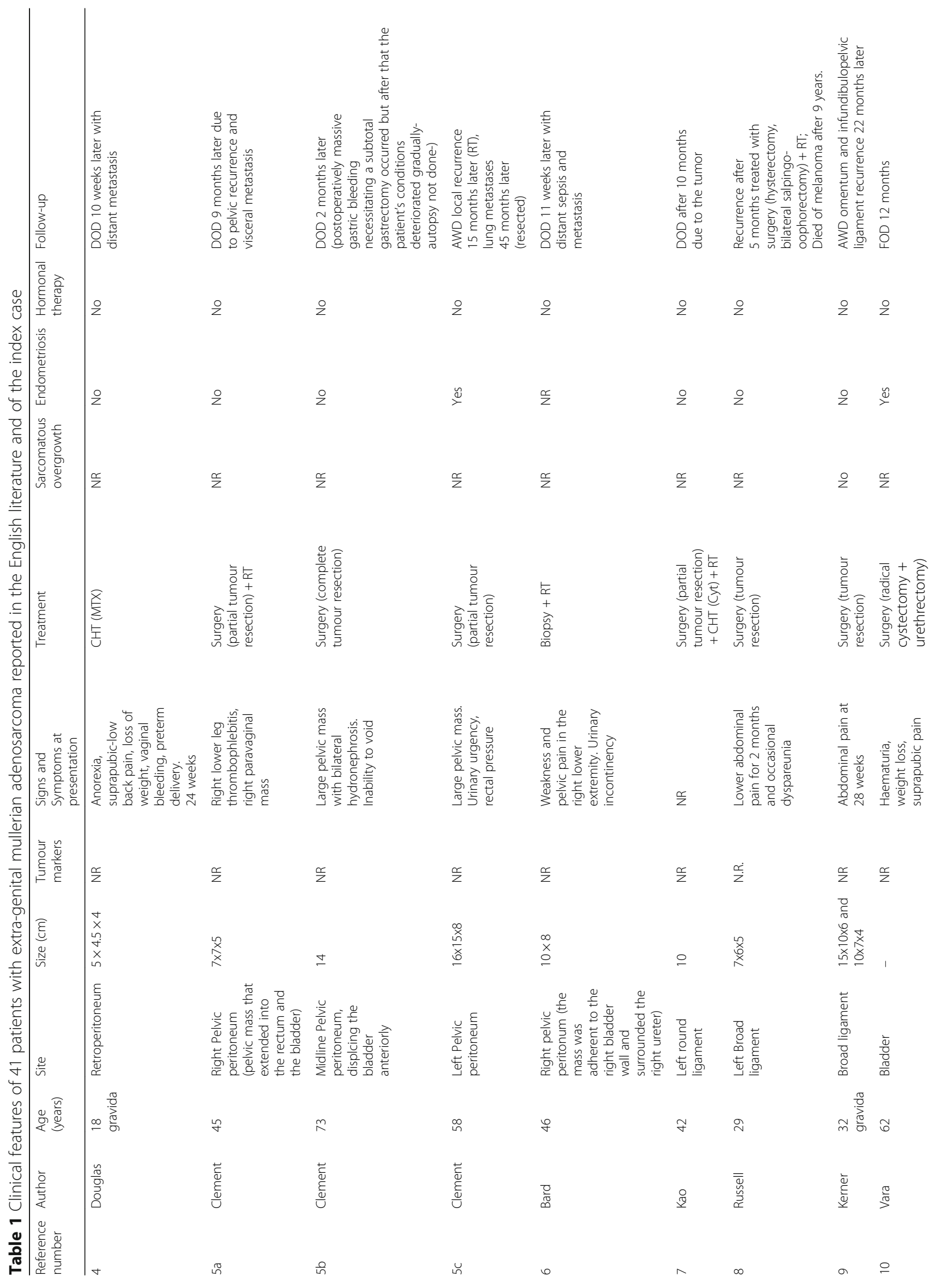




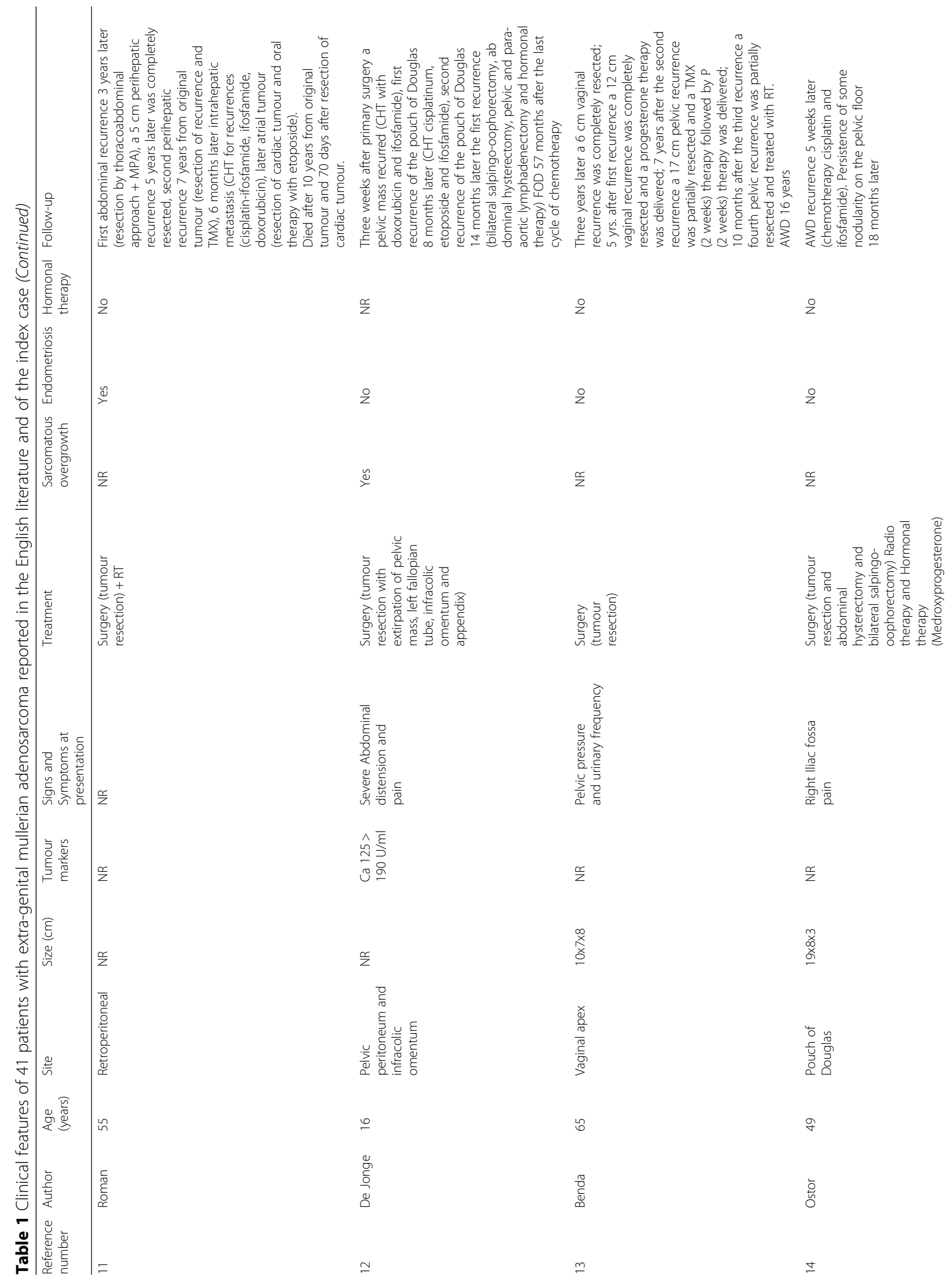




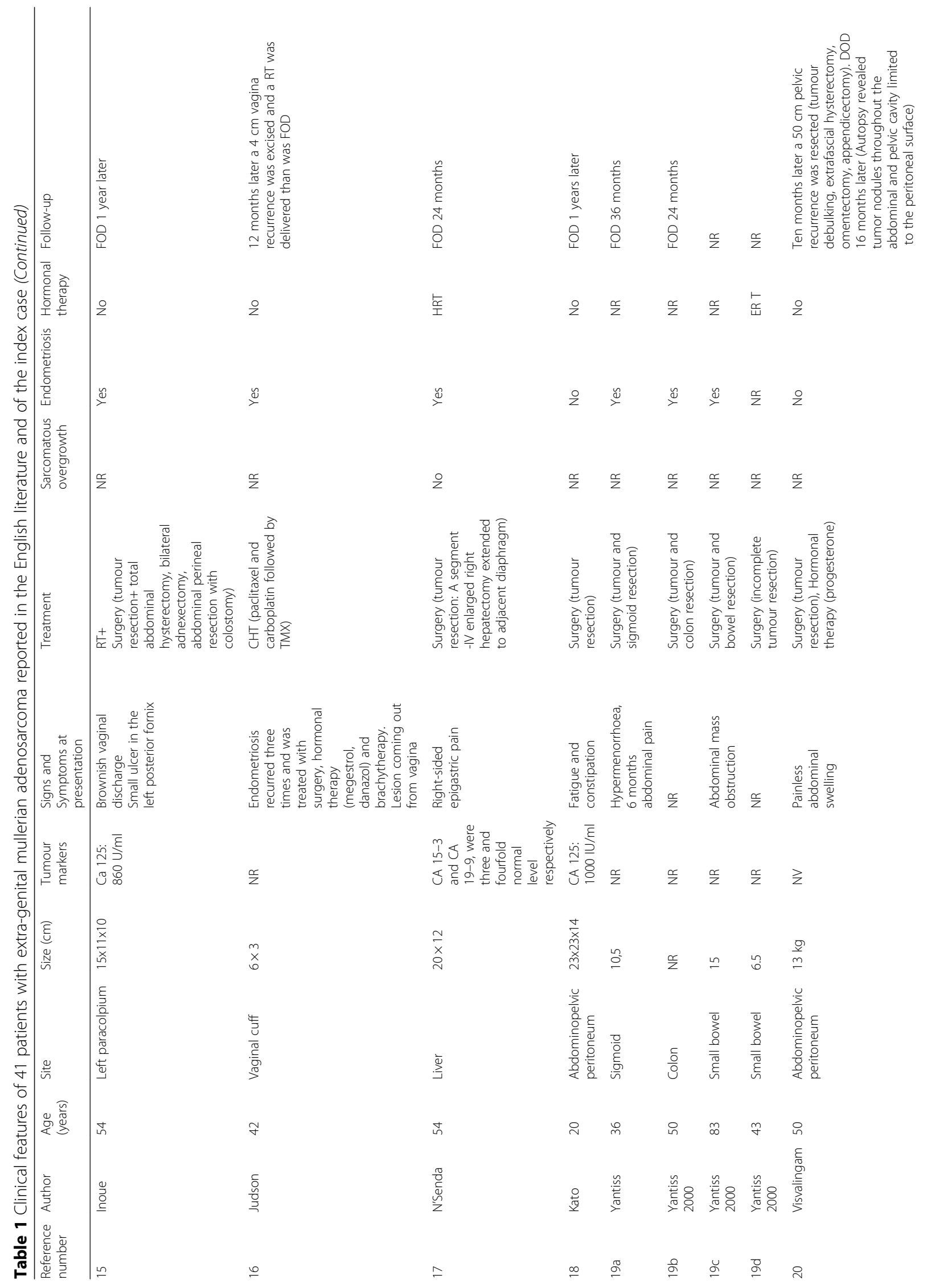




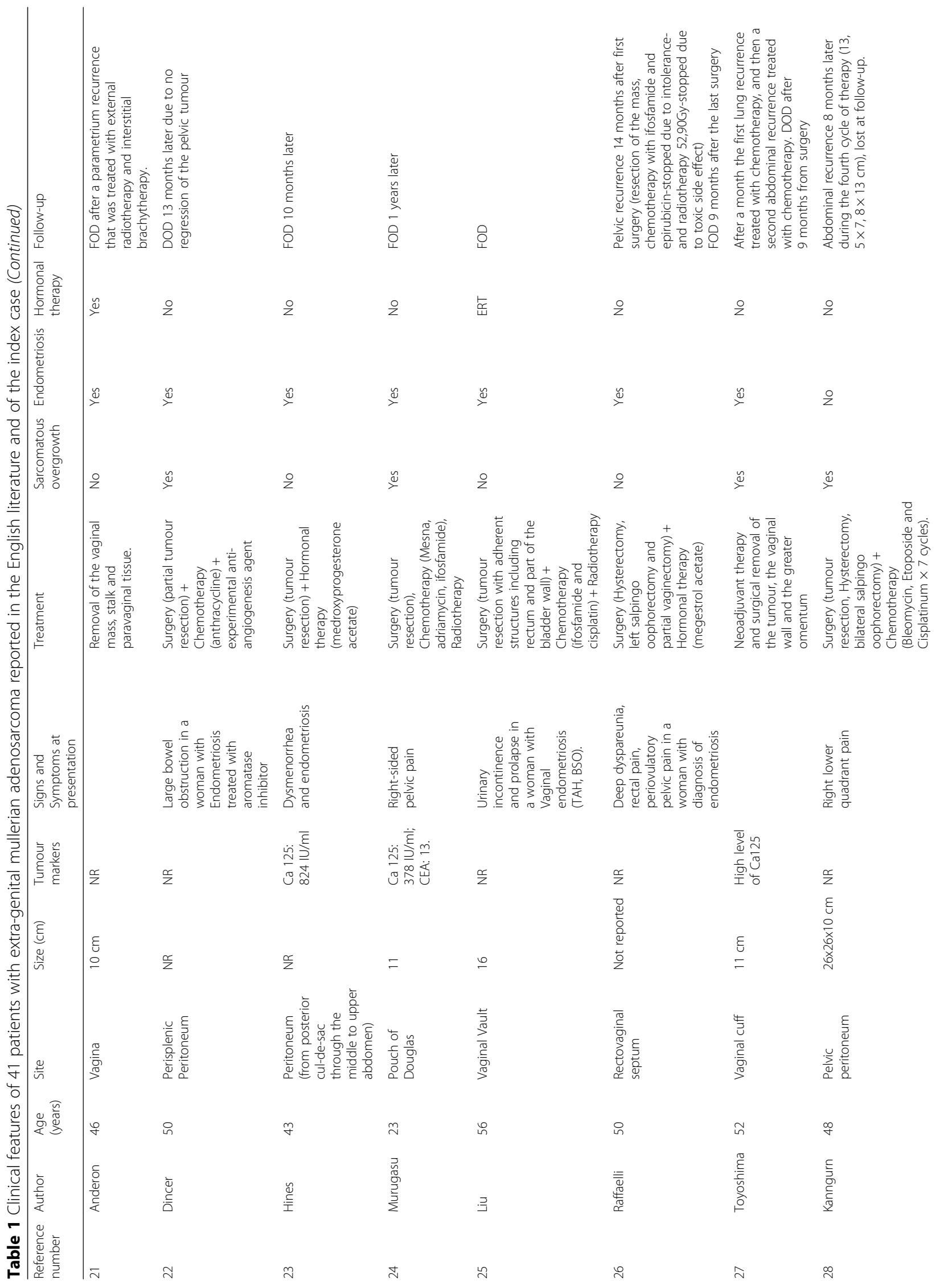




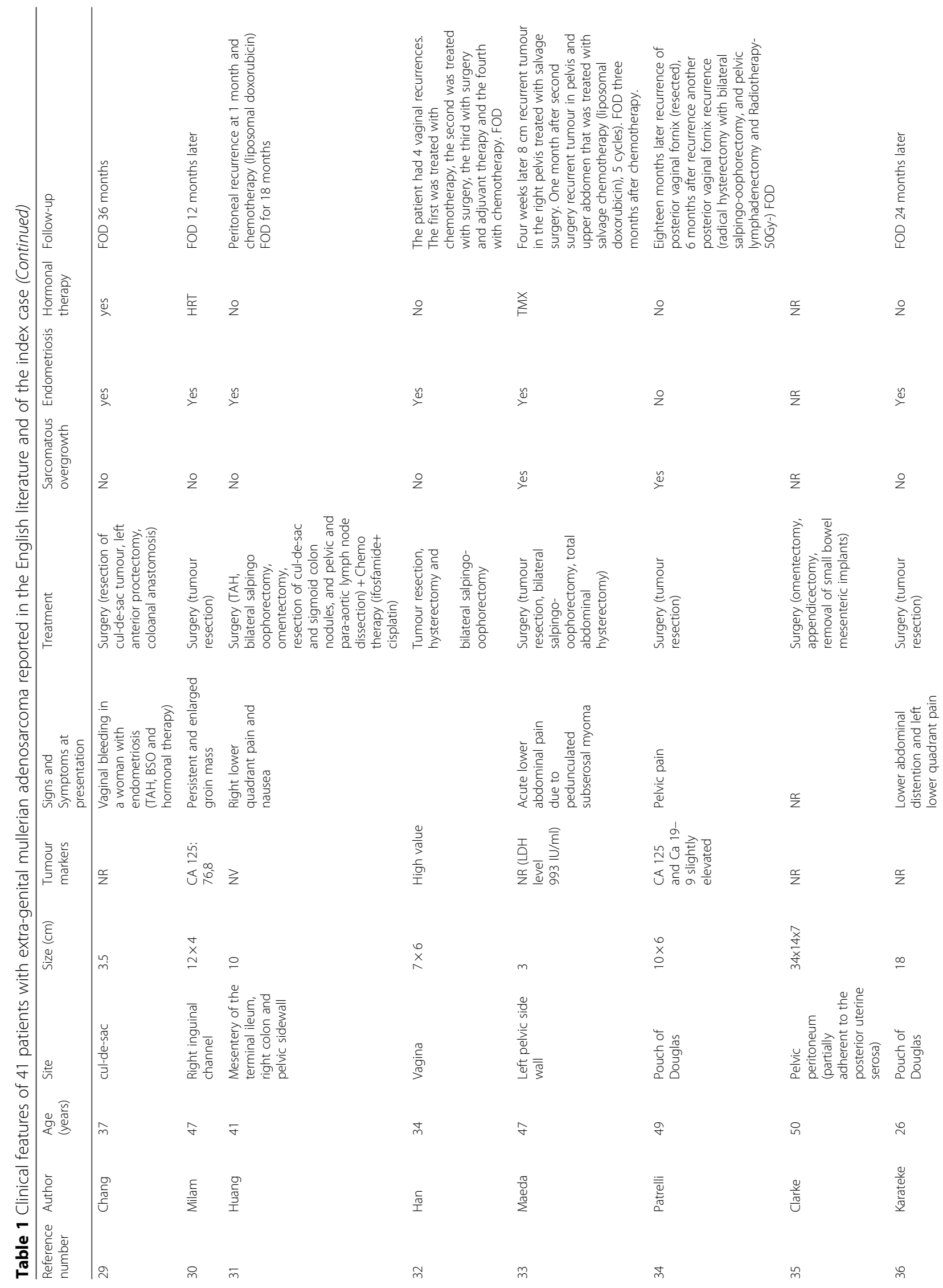


Mandato et al. BMC Cancer (2018) 18:134

Page 8 of 18

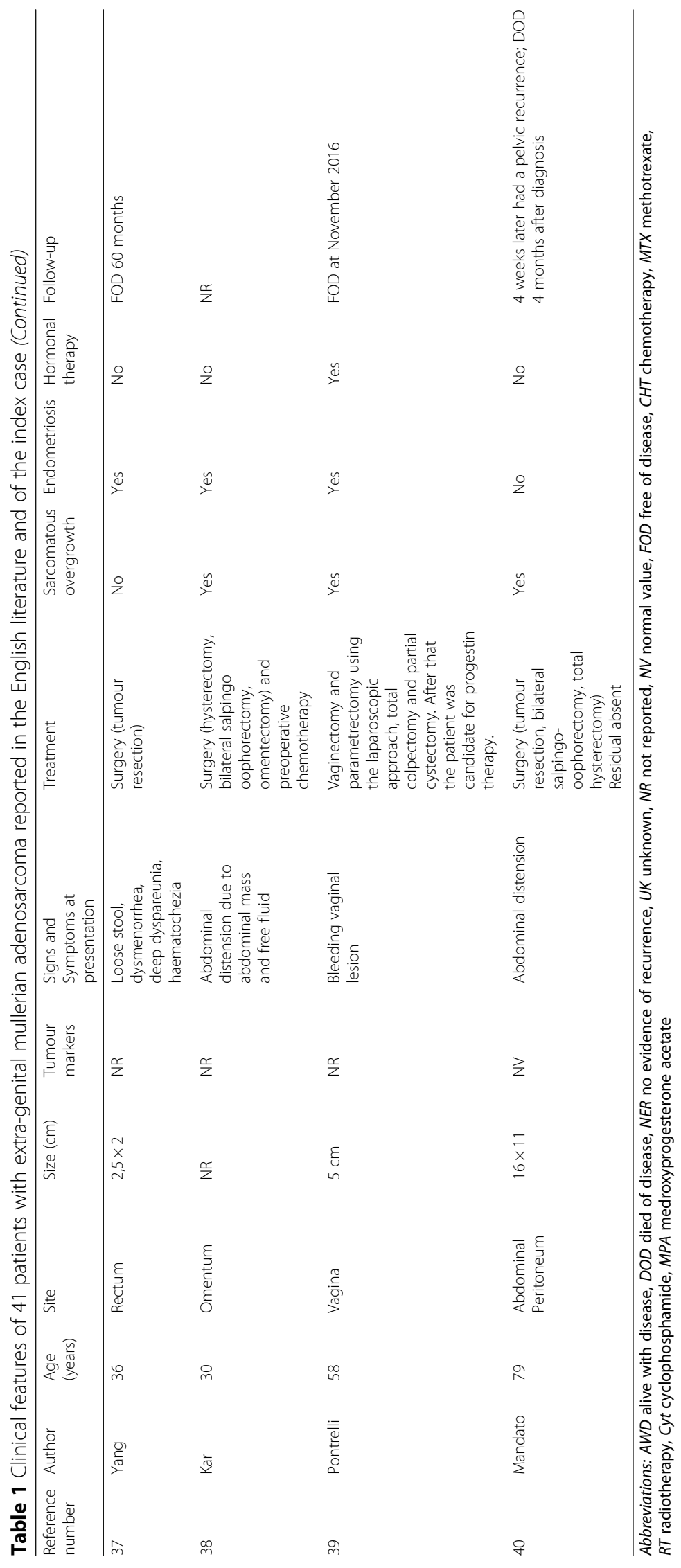




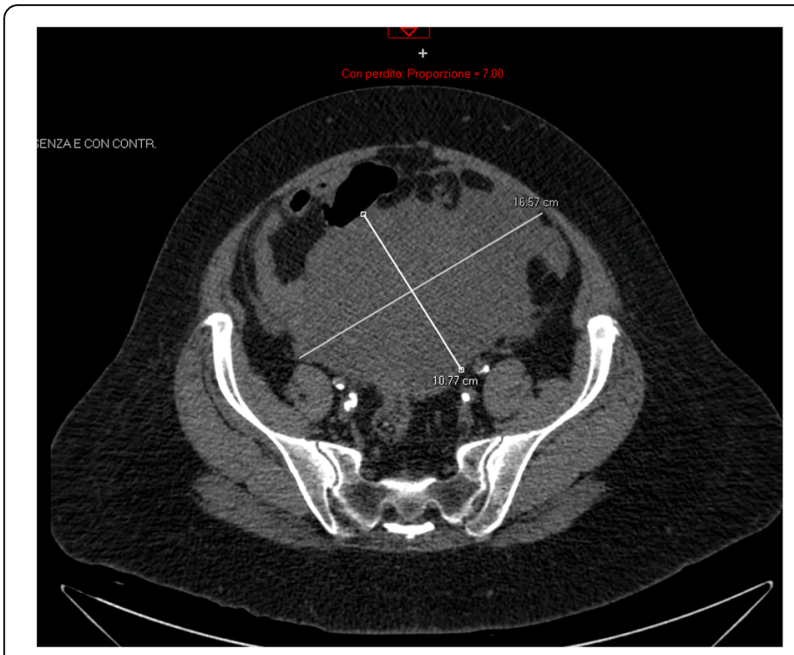

Fig. 1 Computed tomography scan showing a mass of $16 \times 11 \mathrm{~cm}$

She complained only of abdominal distension and pressure. A transvaginal and transabdominal ultrasound examination revealed a multicystic mass resembling an ovarian tumour arising from the pelvis and extending up to the abdomen. Three weeks later, a laparotomy was performed, and a peritoneal mass arising from Douglas peritoneum was found and resected. The uterus and adnexa appeared normal, and a supra-cervical hysterectomy with bilateral salpingooophorectomy was performed. On frozen sections, the mass was identified as a primary sarcoma of the peritoneum with areas of chondroliposarcoma and rhabdomyosarcoma differenzation. No macroscopic residual disease was present (R0). Final pathology diagnosed a malignant peripheral nerve sheath tumors with divergent differentiation (osteosarcoma, chondrosarcoma, angiosarcoma rhabdomyosarcoma, glandular component), grade 3 according to the French Federation of Cancer Centers Sarcoma Group (FNCLCC) grading system.

Adjuvant chemotherapy was planned. Four weeks later, a pre-chemotherapy CT scan revealed a new, multicystic mass $(27 \times 15 \mathrm{~cm})$ (Fig. 2) with impregnation of the wall, strictly adhering to the inferior side of the sigmoid colon and cecal profile and to the superior side of the bladder. The mass protruded into the left inguinal canal by $2 \mathrm{~cm}$. The patient presented with bilateral hydroureteronephrosis, fever due to wound infection, loss of appetite and weakness. Antibiotic therapy, bilateral stents, and support therapy were administered. Due to the progressive poor condition, the patient died 4 months after diagnosis. Histological slides were reviewed by two external independent expert pathologists (A.P. Dei Tos, Chief of Department of Pathology, Treviso Regional Hospital, Treviso, Italy. C.D.M. Fletcher, Chief of Surgical Pathology, Brigham And Women's Hospital, Boston, USA) and the final diagnosis was of extra-genital AS with sarcomatous overgrowth (Figs. 3 and 4).

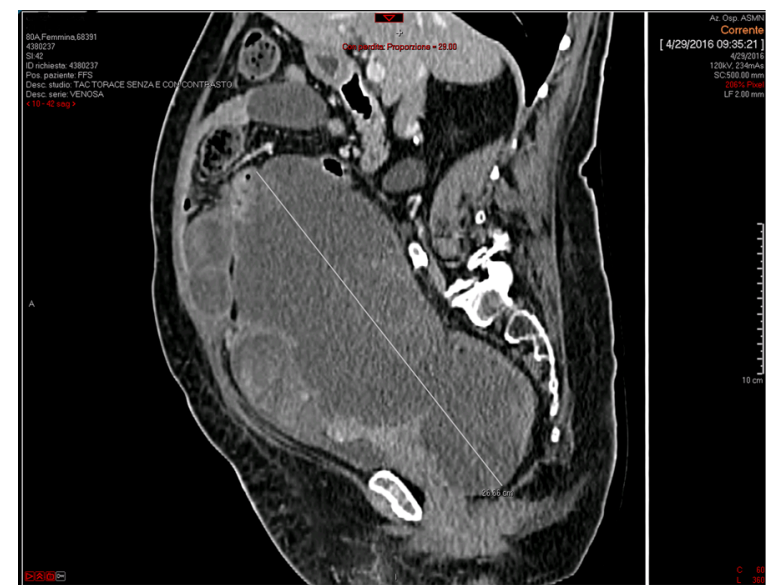

Fig. 2 Pre-chemotherapy computed tomography scan taken 4 weeks after surgery revealing a new, multicystic mass $(27 \times 15 \mathrm{~cm})$

\section{Results}

Clinical features

Table 1 shows the main clinical features of all 41 AS cases reported in literature and of our case.

The 41 affected patients ranged in age from 16 to 83 years (mean, 44.5 years) at presentation, and 2/41 (4.9\%) patients were pregnant at the time of diagnosis.

Overall, 12/32 (37.5\%) patients presented with an extragenital AS arising from the pelvic peritoneum, 5/32 (15.6\%) presented with an AS arising from the pouch of Douglas, $2 / 32$ (6.3\%) presented with an AS arising from the retroperitoneum, 3/32 (9.4\%) presented with an AS arising from the broad ligament, $3 / 32(9.4 \%)$ presented with an AS arising from the colon, $2 / 32(6.3 \%)$ presented with an AS arising from the small bowel, 1/32 (3.1\%) presented with an AS arising from the bladder, 1/32 (3.1\%) presented with AS arising from the omentum, 1/32 (3.1\%) presented with an AS arising from the inguinal canal, 1/32 (3.1\%) presented with an AS arising from the liver, and 1/32 (3.1\%) presented with an AS arising from the mesentery of the terminal ileum. Overall, 9/41 (21.9\%) patients had an AS localized in the vagina: $7 / 9$ (77.8\%) cases were in the vaginal cuff, $1 / 9$ (11.1\%) case was in the paracolpium, and 1/9 (11.1\%) case was in the recto-vaginal septum.

Information on tumour size was available for 33/41 (80.5\%) patients. The sized ranged from 2.5 to $34 \mathrm{~cm}$ with a mean size of $12.2 \mathrm{~cm}(\mathrm{SD}+/-6.0)$. Tumour weight was reported for 1 case (13 k) [20].

Symptoms were reported for $34 / 41$ (82.9\%) patients. Abdominal/pelvic pain was reported for 14/34 (41.2\%) patients, urinary disorders for $9 / 34$ (26.5\%), anorexiaweight loss for $3 / 34(8.8 \%)$, abdominal pressure for $3 / 34$ (8.8\%), dysmenorrhea for $2 / 34$ (5.9\%), bleeding for $4 / 34$ (11.8\%), constipation for $1 / 34$ (2.9\%), low back pain for $1 / 34$ (2.9\%), fatigue for $1 / 34$ (2.9\%) and thrombophlebitis for $1 / 34(2.9 \%)$. 


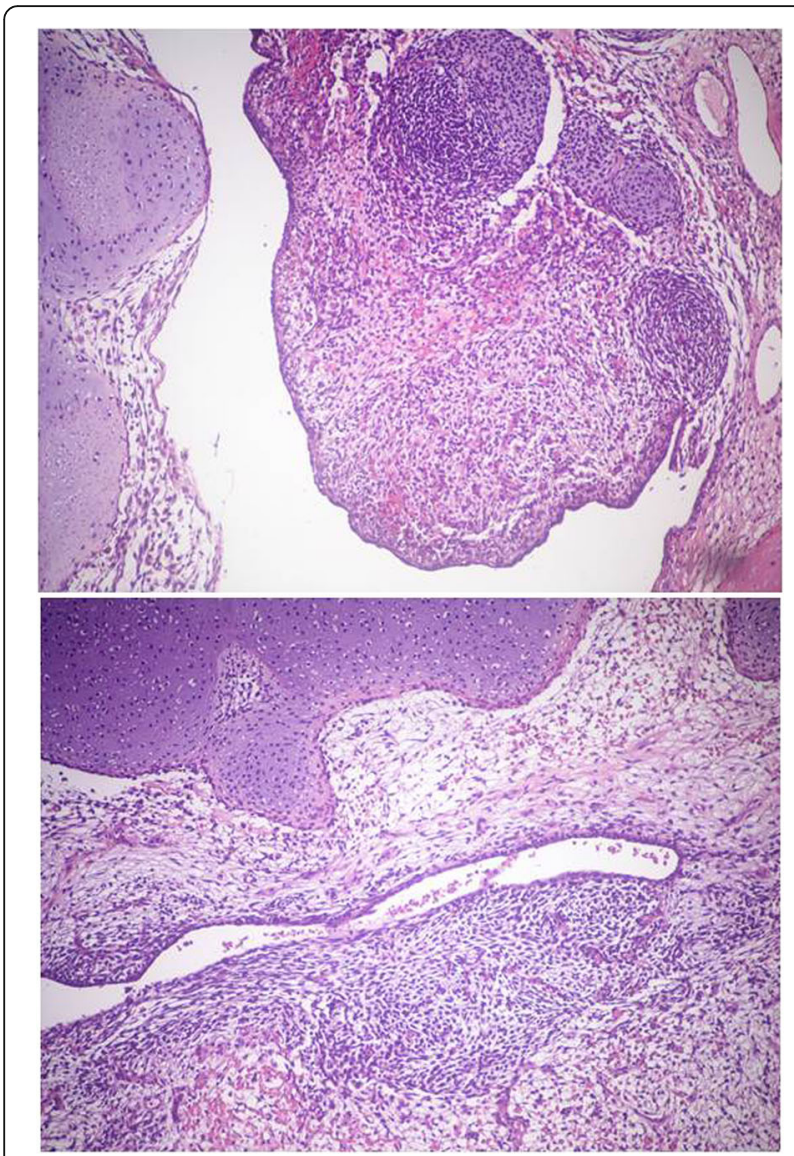

Fig. 3 Medium-power view of the neoplasia, showing both the epithelial component and the undifferentiated spindle cell component, admixed with areas of cartilaginous differentiation (haematoxylin-eosin stain, 10X)

Tumor markers were reported in 13/41 (31.7\%) patients, two patients had normal value $[20,31]$ and 11 patients had elevated value $[12,15,17,18,23,24,27,30,32-34]$ (Table 1). Seven of eleven (63.6\%) patients had elevated serum levels of CA 125 [12, 15, 18, 23, 27, 30, 32], 2/11 (18.2\%) patients had elevated serum levels of both CA 125 and CA 19-9 [17, 34], 1/11 (9.1\%) patient had elevated serum levels of both CA125 and CEA [24], 1/11 (9.1\%) had elevated serum level of LDH [33].

Overall, 8/41 (19.5\%) patients had received hormonal therapy: two patients received hormone replacement therapy (HRT) [17, 30], two patients received oestrogenic replacement therapy $[19 \mathrm{~d}, 25]$, one patient received tamoxifen [16], one patient received oestrogen-progestin therapy [39], and in two patients the hormonal therapy was not specified $[21,29]$.

\section{Treatment}

AS was treated by surgical resection in $38 / 41$ (92.7\%) patients: $5 / 38(13.2 \%)$ patients underwent partial resection, and $33 / 38$ (86.8\%) underwent total resection. Of the 38 patients who received surgical treatment, 18 (47.4\%)
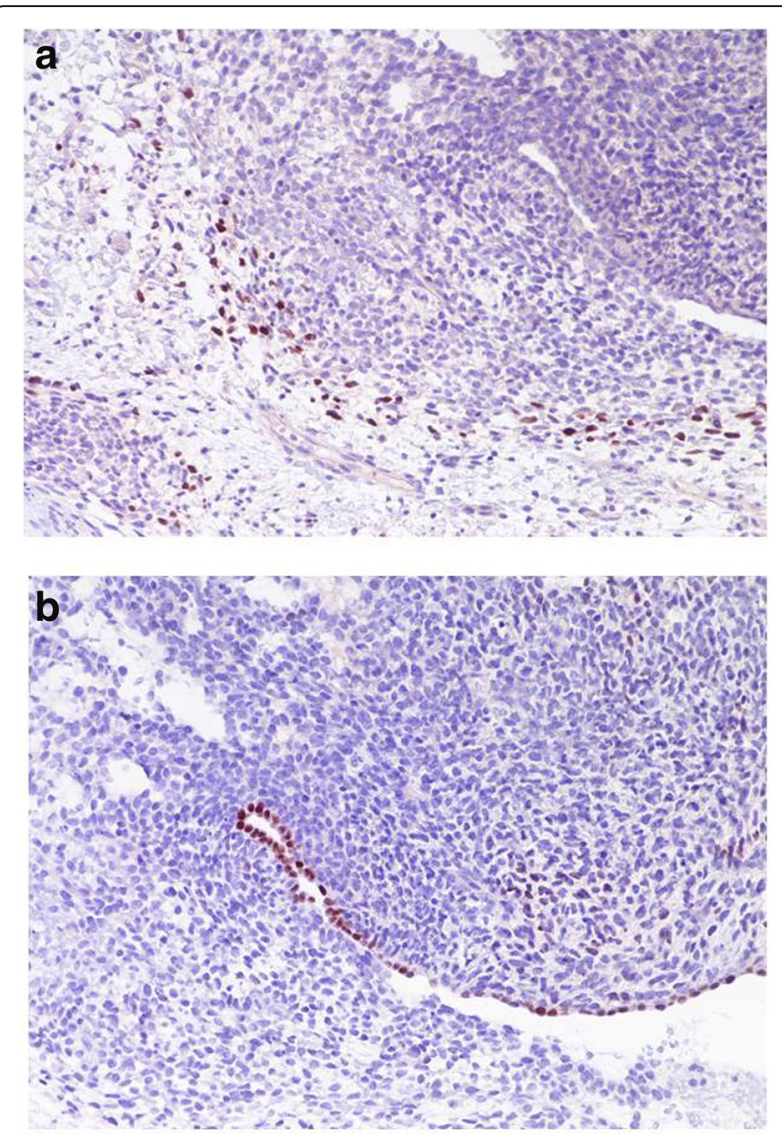

Fig. 4 (a) Small areas with rhabdomyoblastic differentiation within the spindle cell areas (myogenin immunostain, haematoxylin counterstain, 20X); (b) Epithelial clefts within the neoplastic undifferentiated spindle cells highlighted by PAX8 immunohistochemical stain (PAX8 immunostain, haematoxylin counterstain, 20X)

underwent resection of only the tumour [5abc, 7, 8, 9, 11, 13, 18, 19d, 20, 22, 23, 24, 30, 34, 36, 37]; four (10.5\%) underwent tumour resection, hysterectomy and bilateral salpingo-oophorectomy [14, 28, 32, 38]; and 16 (42.1\%) underwent extensive surgery involving other organs such as the bowel $[12,15,19 a, 19 b, 19 c, 25,29,31$, 35 ] and liver [17].

Moreover, 12/38 (31.69\%) patients had received previous total hysterectomy with bilateral salpingooophorectomy for benign disease $[5 \mathrm{~A}, 5 \mathrm{~B}, 5 \mathrm{C}, 6$, $10,11,13,16,17,22,25,29]$; $15 / 38$ (39.5\%) patients received total hysterectomy with bilateral salpingooophorectomy for AS treatment $[8,14,15,19 \mathrm{~A}, 19 \mathrm{~B}$, 20,22,23,26,28,30-33, 35,38]. Particularly, 13 patients were younger than 40 years at the diagnosis of AS and 4/13 (30.8\%) underwent total hysterectomy with bilateral oophorectomy for AS treatment. In 13/41 (31.7\%) patients menopausal status was not reported. Moreover, 17/41 (41.5\%) [5a-c, 6, 10, 11, 13,16, 17, 19c, 21, $22,25,27,29,30,39]$ patients were in postmenopausal 
stage, $11 / 41(26.8 \%)$ patients were at premenopausal stage $[4,8,9,12,14,18,24,31,36-38]$ and $4 / 11$ $(36.4 \%)$ received bilateral salpingo-oophorectomy during AS treatment $[8,14,31,38]$.

Overall, 16/38 (36.6\%) surgical patients received additional therapy: $13 / 38$ (34.2\%) received adjuvant therapy, and $3 / 38(7.9 \%)$ received neo-adjuvant therapy [5a, 7, 11, $14,20,22,23,24,25,26,28,31,39]$. Additionally, 3/38 (7.9\%) patients received chemotherapy [22, 28, 31], 2/38 (5.3\%) patients received radiotherapy $[5 \mathrm{a}, 11], 3 / 13$ (7.9\%) patients received chemo-radiotherapy [7, 24, 25], $4 / 38(10.5 \%)$ patients received hormonal therapy [20, 23, $26,39]$, and $1 / 38(2.6 \%)$ patient received radiotherapy and hormonal therapy [14]. In total, $2 / 38$ (5.3\%) patients were treated with neoadjuvant chemotherapy [14 (methotrexate), 27], and 1/38 (2.6\%) patient was treated with neoadjuvant radiotherapy [15].

AS was not treated with surgery in 3/41 (7.3\%) patients. In the first patient AS was misdiagnosed with coriocarcinoma and was treated with chemotherapy but at postmortem examination the final diagnosis of retroperitoneal AS was done [4]. The second patient had received a hysterectomy for leiomyoma twenty years before underwent to diagnostic laparoscopy for right pelvic mass. At laparoscopy both ovaries were normal and a biopsy of the mass diagnosed an AS. The second patient was treated with only radiotherapy [6]. The third patient had received a hysterectomy for leiomyoma 4 years before multiple vaginal operations for recurrent vaginal endometriosis were performed [16]. The third patient was treated with chemotherapy and hormonal therapy (tamoxifen) [16].

\section{Risk factors}

A total of $25 / 41$ (61.0\%) patients had received a previous diagnosis of endometriosis [5c-10-11-15-16-17-19abc-2122-23-24-25-26-27-29-30-31-32-33-36-37-38,39] (Table 2).

Endometriosis treatment was not reported for $18 / 25$ $(72 \%)$ patients $[5 c, 10,11,15,17,19 a b c, 23,24,26,30,31,33,36$ ,37,38], endometriosis was surgically and hormonally treated in $2 / 25(8 \%)$ patients $[29,39]$, it was treated surgically in $3 / 25(12 \%)$ patients $[21,25,27]$, it was treated hormonally (aromatase inhibitor) in 1/25 (4\%) patient [22], and it was treated with surgery, hormonal therapy and brachytherapy in $1 / 25$ (4\%) patient [16]. Overall, 17/25 (68\%) patients with endometriosis had an AS with extra-genital localization [5c-10-11-17-19abc-22-23-24-29-30-31-33-36$37-38$ ], and $8 / 25$ (32\%) patients had a vaginally localized tumour [15-16-21-25-26-27-32-39]. Moreover, 8/25 (32\%) patients showed elevated levels of tumour markers $[15,17$, $23,24,27,30,32,33]$. A total of $7 / 25$ patients received previous hormonal therapy $[17,21,25,29,30,33,39]: 2 / 7$ $(28,6 \%)$ received HRT $[17,30], 1 / 7$ received (14.3\%) ERT [25], 1/7 (14.3\%) received TMX [33], 1/7 (14.3\%) received oestrogenic-progestinic therapy [39], and 2/7 (28,6\%) received unspecified hormonal therapy [21, 29].

Overall, 6/25 (24\%) patients with endometriosis showed sarcomatous overgrowth [22, 24, 27, 33, 38, 39]: 13/25 (52\%) were only surgically treated [5c-10-17-19abc-21-29-30-3233-36-37], 10/25 (40\%) were treated with surgery and adjuvant therapy [11-15-22-23-24-25-26-31-38-39], 1/25 (4\%) was treated with neoadjuvant chemotherapy and surgery [27], and 1/25 (4\%) was treated with chemotherapy and hormonal therapy without surgery [16].

Heterologous sarcomatous elements were present in 4/41 (9.7\%) patients $[9,12,16,18]$, endometriosis was present in one patient [16,], sarcomatous overgrowth was present in one patient [12], surgery was performed in three cases [9, $12,18]$, one case received chemotherapy and tamoxifen [16].

\section{Follow-up data}

Follow-up information was available for 35/41 (85.4\%) patients (Table 2); 1/41 (2.4\%) patient died from a cause other than AS, and 5/41 (12.2\%) were lost to follow-up. At the time of follow-up, 22/35 (62.9\%) patients were alive and free of disease (FOD), 9/35 (25.7\%) patients had died of disease (DOD), and 4/35 (11.4\%) patients were alive with disease (AWD).

In the group of nine DOD patients, 4/9 (44.4\%) patients died for relapse [5a,11, 20, 27], 1/9 (11.1\%) [7] died for progression of disease, $1 / 9$ (11.1\%) patient died for treatment complication (postoperatively massive gastric bleeding) [5b], $1 / 9(11.1 \%)$ patient died for persistent pelvic tumor [22r] and 2/9 (22.2\%) patients died for distant metastasis $[4,6]$.

Information on follow-up time was available for 34 patients: the mean follow-up was 27 months (range, 1192). Eighteen patients relapsed [5a, 5c, 8, 9, 11, 12, 13, 14, $16,20,21,26,27,28,31,32,33,34]$, and their mean DFS was 11.8 months (range, 1-36). Two cases were lost to follow-up after recurrence. For the $9 / 35$ (5.7\%) patients who died due to disease [4, 5a, 5b, 6, 7, 11, 20, 22, 27], 8/9 (88.9\%) patients had extra-genital AS, and 1/9 (11.1\%) had vaginal AS [27]. Additionally, 2/9 (22.2\%) patients showed both sarcomatous overgrowth and endometriosis [22, 27]. None of these patients received previous hormonal therapy. Of the patients who died because of AS, 4/9 (44.4\%) had experienced a relapse [5a, 11, 20, 27]. The number of relapses ranged from one to five with a mean of two. The most common localization for first relapse was the pelvis, but one patient's first relapse was in the lung [27]. In total, $2 / 4(50 \%)$ patients with relapse were surgically treated $[11,20], 1 / 4(25 \%)$ was not treated [5a], and $1 / 4$ (25\%) received only chemotherapy. One patient [11] relapsed additional times at prehepatic/intrahepatic sites and in the heart and received multimodal treatment; another patient [27] had a second abdominal recurrence and was treated with chemotherapy. Of the patients who died from disease, the mean OS was 
Table 2 Clinical features and follow up data of 41 extra-uterine and extra-ovarian mullerian adenosarcoma according to histological features

\begin{tabular}{|c|c|c|c|c|c|c|c|c|c|c|}
\hline & \multirow{2}{*}{$\begin{array}{l}\text { Total } \\
\text { population } \\
n=41 \\
n(\%)\end{array}$} & \multicolumn{2}{|c|}{ Endometriosis } & \multirow[t]{2}{*}{$P$ value } & \multicolumn{2}{|l|}{ Overgrowth } & \multirow[t]{2}{*}{$P$ value } & \multicolumn{2}{|c|}{$\begin{array}{l}\text { Heterologous } \\
\text { sarcomatous differentiation }\end{array}$} & \multirow[t]{2}{*}{$P$ value } \\
\hline & & $\begin{array}{l}\text { No } n=16 \\
\mathrm{n}(\%)\end{array}$ & $\begin{array}{l}\text { Yes } n=25 \\
\mathrm{n}(\%)\end{array}$ & & $\begin{array}{l}\text { No } n=32 \\
\mathrm{n}(\%)\end{array}$ & $\begin{array}{l}\text { Yes } n=9 \\
\mathrm{n}(\%)\end{array}$ & & $\begin{array}{l}\text { No } n=37 \\
\mathrm{n}(\%)\end{array}$ & $\begin{array}{l}\text { Yes } n=4 \\
\mathrm{n}(\%)\end{array}$ & \\
\hline Age (mean $\pm S D)$, years & $44.5 \pm 15.0$ & $43.1 \pm 15.8$ & $45.5 \pm 12.7$ & 0.597 & $45.4 \pm 13.9$ & $41.4 \pm 14.6$ & 0.463 & $46.4 \pm 13.0$ & $27.5 \pm 11.8$ & 0.009 \\
\hline Size (mean $\pm S D), m m$ & $12.2 \pm 6.9$ & $13.4 \pm 8.3$ & $11.0 \pm 5.3$ & 0.319 & $12.5 \pm 6.7$ & $11.0 \pm 8.1$ & 0.659 & $11.9 \pm 6.8$ & $14.7 \pm 8.5$ & 0.517 \\
\hline Site & & & & 0.066 & & & 1 & & & 1 \\
\hline Extra-genital & $32(78.0)$ & $15(93.8)$ & $17(68.0)$ & & $25(78.1)$ & $7(77.8)$ & & $29(78.4)$ & $3(75.0)$ & \\
\hline Vagina & $9(22.0)$ & $1(6.2)$ & $8(32.0)$ & & $7(21.9)$ & $2(22.2)$ & & $8(21.6)$ & $1(25.0)$ & \\
\hline Endometriosis & & & & & & & 1 & & & 0.281 \\
\hline No & $16(39.0)$ & - & - & - & $13(40.6)$ & $3(33.3)$ & & $13(35.1)$ & $3(75.0)$ & \\
\hline Yes & $25(61.0)$ & - & - & - & $19(59.4)$ & $6(66.7)$ & & $24(64.9)$ & $1(25.0)$ & \\
\hline Overgrowth & & & & 1 & & & & & & 1 \\
\hline No & $32(78.0)$ & $13(81.3)$ & $19(76.0)$ & & - & - & & $29(78.4)$ & $3(75.0)$ & \\
\hline Yes & $9(22.0)$ & $3(18.7)$ & $6(24.0)$ & & - & - & & $8(21.6)$ & $1(25.0)$ & \\
\hline Treatment & & & & 0.557 & & & 1 & & & 0.101 \\
\hline Surgery & $22(53.7)$ & $9(56.3)$ & $13(52.0)$ & & $18(56.3)$ & $4(44.4)$ & & $19(51.4)$ & $3(75.0)$ & \\
\hline $\begin{array}{l}\text { Surgery }+ \text { additional } \\
\text { treatments }\end{array}$ & $16(39.0)$ & $5(31.2)$ & $11(44.0)$ & & $11(34.4)$ & $5(55.6)$ & & $16(43.2)$ & $0(0.0)$ & \\
\hline No Surgery & $3(7.3)$ & $2(12.5)$ & $1(4.0)$ & & $3(9.4)$ & $0(0.0)$ & & $2(5.4)$ & $1(25.0)$ & \\
\hline Surgical Approach & & & & 0.345 & & & 1 & & & 0.327 \\
\hline Complete resection & $33(80.5)$ & $11(68.8)$ & $22(88.0)$ & & $25(78.1)$ & $8(88.9)$ & & $30(81.1)$ & $3(75.0)$ & \\
\hline Partial resection & $5(12.2)$ & $3(18.7)$ & $2(8.0)$ & & $4(12.5)$ & $1(11.1)$ & & $5(13.5)$ & $0(0.0)$ & \\
\hline No surgery & $3(7.3)$ & $2(12.5)$ & $1(4.0)$ & & $3(9.4)$ & $0(0.0)$ & & $2(5.4)$ & $1(25.0)$ & \\
\hline Lost in follow up & $6(14.6)$ & 4 & 2 & & 4 & 2 & & 6 & 0 & \\
\hline $\begin{array}{l}\text { Status at last follow up } \\
\text { (35 patients) }\end{array}$ & & & & 0.002 & & & 0.843 & & & 0.278 \\
\hline FOD & $22(62.9)$ & $3(25.0)$ & 19 (82.6) & & $17(60.7)$ & $5(71.4)$ & & $19(61.3)$ & $3(75.0)$ & \\
\hline AWD & $4(11.4)$ & $3(50.0)$ & $1(4.3)$ & & $4(14.3)$ & $0(0.0)$ & & $3(9.7)$ & $1(25.0)$ & \\
\hline DOD & $9(25.7)$ & $6(25.0)$ & $3(13.0)$ & & $7(25.0)$ & $2(28.6)$ & & $9(29.0)$ & $0(0.0)$ & \\
\hline Recurrence & $18(51.4)$ & $9(56.2)$ & $9(36.0)$ & 0.184 & $13(40.6)$ & $5(55.5)$ & 0.447 & $15(45.5)$ & $3(75.0)$ & 0.340 \\
\hline More than 1 recurrence & $9(25.7)$ & $4(28.6)$ & $5(21.7)$ & 1 & $5(17.9)$ & $4(57.1)$ & 0.294 & $7(18.9)$ & $2(50.0)$ & 1 \\
\hline Death patients OS (mean \pm sd) & & $7.0 \pm 5.7$ & $46.3 \pm 63.9$ & 0.151 & $6.0 \pm 4.0$ & $16.7 \pm 17.8$ & 0.179 & $20.1 \pm 37.8$ & - & * \\
\hline $\begin{array}{l}\text { Patients with recurrence DFS } \\
\text { (mean } \pm \text { sd) }\end{array}$ & & $47.9 \pm 63.6$ & $28.0 \pm 41.3$ & 0.486 & $12.2 \pm 11.4$ & $11.4 \pm 12.6$ & 0.897 & $11.9 \pm 12.1$ & $11.6 \pm 10.5$ & 1 \\
\hline
\end{tabular}

AWD alive with disease, DOD died of disease, FOD free of disease

*comparison was not possible, because no patients with heterologous sarcomatous differentiation dead during follow up

20.1 months (range, 2-120), and of the subgroup of patients who died after recurrence, the mean DFS was 14 months (range, 1-36). At the time of publication, 4/ $36(11.1 \%)$ patients were alive with disease [5c, 9, 13, 14]: 3/4 (75\%) had an AS with extra-genital localization $[5 \mathrm{c}, 9,14]$, and $1 / 4(25 \%)$ had an AS with vaginal localization [13]. None experienced sarcomatous overgrowth, and $1 / 4$ (25\%) had a previous diagnosis of endometriosis $[5 \mathrm{c}]$. None had previously received hormonal therapy. All patients alive with disease had at least one relapse. The number of relapses ranged from one to four with a mean of 2.2 (Table 2). Overall, 22/35 $(62.9 \%)$ patients were FOD at the time of publication.
Of these, $14 / 22(63.6 \%)$ had not experienced relapse $[10,15,17,18,19 a b, 23,24,25,29,30,36,37,39], 11 /$ $14(78.5 \%)$ had an AS with extra-genital localization $[10,17,18,19 a b, 23,24,29,30,36,37], 3 / 14(21.4 \%)$ had an AS with vaginal localization $[15,25,39], 2 / 14$ (14.3\%) had a tumour with sarcomatous overgrowth [24], 13/14 (92.8\%) had a previous diagnosis of endometriosis $[10,15,17,19 \mathrm{ab}, 23,24,25,29,30,36,37$, 39], $9 / 14(64.3 \%)$ were only surgically treated [10, 17 , $18,19 \mathrm{ab}, 29,30,36,37]$, and 5/14 $(35.7 \%)$ were treated with surgery and adjuvant therapy [15, 21, 24, 25, 39]. Additionally, 5/14 (35.7\%) had previously underwent hormonal therapy $[17,25,29,30,39]$. Information on 
follow-up time was available for 13 patients, and the mean follow-up was 21.9 months (range, 1-60 months). A total of $8 / 22(36.4 \%)$ patients were alive and FOD despite having one or more relapses during follow-up $[12,16,20,26,31,32$ 33, 34]. Their number of relapses ranged from one to four with a mean of 1.8 . In $3 / 8$ $(37.5 \%)$ patients, the first relapse was in the pelvis $[12,26,33]$; in $1 / 8(12.5 \%)$ patient, it was in the peritoneum [31]; in $3 / 8(37.5 \%)$ patients, it was in the vagina $[16,32,34]$; and in $1 / 8(12.5 \%)$ patient, it was in the parametrium [21]. The first relapse was surgically treated in $2 / 8(25 \%)$ patients $[33,34]$, it was treated with surgery and adjuvant therapy in $2 / 8$ (25\%) patients $[16,26]$, and it was treated with only chemotherapy $[12,31,32]$ or only radiotherapy and brachytherapy [21] in 4/8 (50\%) patients. Overall, 4/8 (50\%) patients experienced a second relapse [12, 32-34]: 1/4 (25\%) patient's second relapse location was in the pouch of Douglas [12], 1/4 (25\%) patient's relapse was in the pelvic peritoneum [33], and $2 / 4$ (50\%) patients' relapses were in the vagina $[32,34]$. In $2 / 4(50 \%)$ patients, the second recurrence was treated only with chemotherapy [12, 33], whereas in $1 / 4$ (25\%) patient, it was treated with surgery and adjuvant therapy, and in $1 / 4(25 \%)$ patient, it was surgically treated. In total, 2/8 (25\%) patients had a third relapse: one was in the pouch of Douglas and was treated with surgery and hormonal therapy [34], and the other was in the vagina and was treated with surgery and adjuvant therapy [32]. Finally, 1/8 (12.5\%) patient experienced a fourth vaginal relapse that was treated only with adjuvant therapy [32].

Information on follow-up time was available for six patients. They had a mean DFS of 7.8 months (range, 118 months) and a mean total follow-up of 21.7 months (range, 1-57).

Of the FOD patients who experienced at least one recurrence during follow-up, 4/8 (50\%) had AS with a peritoneal localization $[12,31,33,34]$ and $4 / 8(50 \%)$ with a vaginal localization [16, 21, 26, 32], 3/8 (37.5\%) showed sarcomatous overgrowth $[12,33,34]$, and $6 / 8(75 \%)$ had a diagnosis of endometriosis [16, 21, 26, 31-33]. In total, 5/8 (62.5\%) patients were only surgically treated [12, 21, 32-34], 2/8 (25\%) were treated with surgery and adjuvant therapy $[26,31]$, and $1 / 8(12.5 \%)$ was treated only with chemotherapy and hormonal therapy [16]. Additionally, 2/8 (25\%) had previously received hormonal therapy.

Kaplan Meier curves were used to evaluate the impact of AS pathological characteristics (endometriosis, sarcomatous overgrowth and site of localization) and AS treatment (no surgery, surgery, complete resection, partial resection and adjuvant therapy) on OS (Fig. 5) and DFS (Fig. 6). Statistical comparison of OS Kaplan Meier curves showed a significant difference in survival distribution (log-rank $P$ value $=0.005$ ) between patients who received different therapy; in particular patients who received only surgery showed a trend of survival higher than those who received both surgery adjuvant therapy or only adjuvant therapy (Fig. 5d). Moreover, patients with AS treated with complete resection presented better OS than women with partially resected AS or not surgically treated AS (log-rank $P$ value $=0.0005)$ (Fig. 5e).

Evaluation of Kaplan Meier curves referred to DFS showed a significant difference in DFS distribution between patients presenting or not presenting a previous diagnosis of endometriosis (log-rank $P$ value $=0.020$ ) Endometriosis resulted to improve DFS of patients with extra-uterine AS (Fig. 6a).

\section{Discussion}

Since 1974, when the first case of an extra-uterine AS was described by Clement and Scully, only 41 cases of extra-uterine or extra-ovarian AS have been reported [3-34] (Table 1).

Here, we reported on 32/41 (78.0\%) patients with extra-genital AS and 9/41 (22.0\%) patients with vaginal AS. The mean age was 44.5 years (range, $16-83$ years; $\mathrm{SD}+/-15)$. The extra-genital AS patients had a mean age of 42.8 years (range, $16-83 ;+-14.7$ ), and the vaginal AS patients had a mean age of 50.8 years (range, $42-$ 65 years; SD +/-9.2). According to previous studies, extra-uterine AS occurs in younger women than uterine AS (median age, 58 years) [1-37].

Unlike prior studies of uterine AS, for which bleeding was the most common presentation symptom [1, 37], in our review, the most common presentation symptom resulted from the large abdominal masses of the AS growths in some patients, with some tumours reaching a size of $34 \mathrm{~cm}$ [35] or $13 \mathrm{k}$ [20]. Typically, extra-uterine AS is a large, partly cystic mass with an irregular and lobulated surface [1]. Heterologous elements have been reported in AS from all sites [22], which might cause misdiagnosis of chondroliposarcoma of the peritoneum. It should also be considered that evaluations of frozen sections are less effective when dealing with a huge mass (maximum size: $27 \mathrm{~cm}$ ). Heterologous elements may portend a poorer prognosis, particularly the rhabdomyoblastic differentiation [46]. Four AS patients included in our review presented heterologous elements $[9,12,16,18]$. They were younger than other AS patients, although $75 \%$ of patients recurred $[9,12,16], 75 \%$ of patients were FOD $[12,16,18]$ at last follow-up (Table 2).

CA 125 was reported in 13/41 (31.7\%) patients and was found to be greater in $11 / 13$ (84.6\%) patients, suggesting an association with peritoneal involvement and sarcomatous overgrowth, as reported by Inoue [15]. In prior studies, CA 125 was reported in 5/10 (40\%) patients [12, 24, 27, 33], and it was found at high levels in $4 / 4(100 \%)$ patients $[12,23,27,30]$. CA 125 titres 

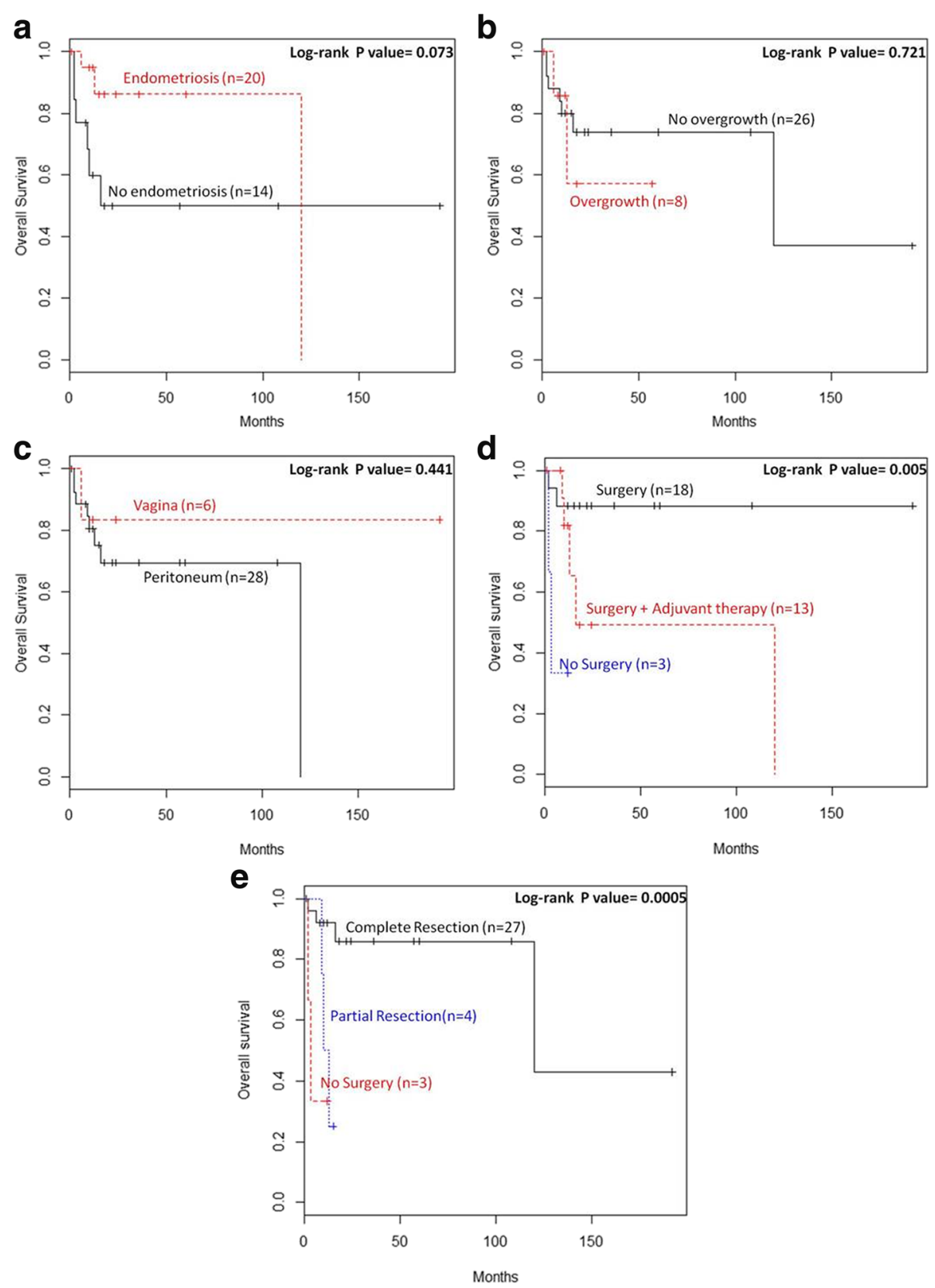

Fig. 5 Impact of (a) endometriosis, (b) sarcomatous overgrowth, (c) site of tumor localization, (d) treatment, (e) surgical approach on OS of patients with extra-uterine AS

have been well correlated with the clinical course of endometriosis associated with extra-uterine AS [30]. In our review, endometriosis was associated with AS in $25 / 41(61 \%)$ patients, being present in $8 / 9(88 \%)$ patients with vaginal AS and in $17 / 33(51.5 \%)$ patients with extra-genital AS.

AS is the second most common gynaecological malignancy in patients with endometriosis after clear cell carcinoma of the ovary [30,47]. A review of pathologic slides from 1000 cases of surgically proven endometriosis found a
$0.3 \%$ rate of AS in cases of extra-ovarian endometriosis [30, 47]. In 2000, Zanetta suggested that chronic stimulation from endogenous or exogenous oestrogen may increase the likelihood of endometriosis-associated carcinogenesis [48].

In our review, only $8 / 41$ (19.5\%) patients received hormonal therapy [17, 19d, 21, 25, 29, 30, 33,39] such as HRT [17, 30] ERT [19d, 25] or tamoxifen [16]. However, we identified only two patients with AS associated with severe refractory endometriosis who required surgery with hormonal therapy [29] and one patient who 

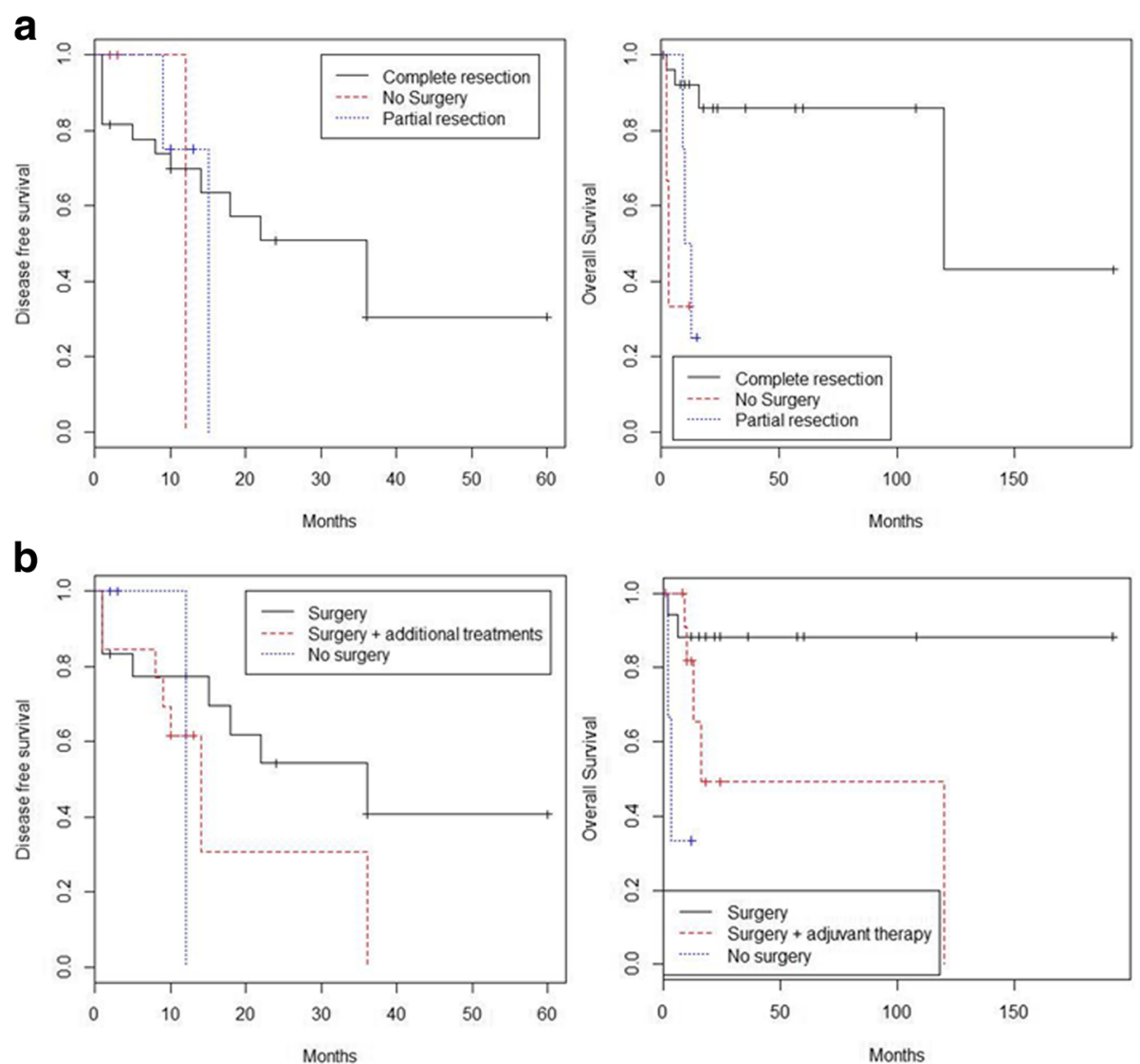

Fig. 6 Impact of (a) endometriosis, (b) sarcomatous overgrowth, (c) site of tumor localization, (d) treatment, (e) surgical approach on DFS of patients with extra-uterine AS

required surgery with hormonal therapy and brachytherapy [16]. Nevertheless, old, recurrent and symptomatic endometriosis should be carefully monitored and possibly excised radically [49].

Although endometriosis may be involved in extrauterine AS tumourigenesis, it is considered a favourable prognostic factor for this tumour type [29, 30]. Patients with AS associated with endometriosis showed increased DFS than AS patients without endometriosis (Fig. 6a).

No endometriosis was found in our patient. In cases of extra-genital AS without endometriosis, the tumour may arise from pluripotent mesothelial and mesenchymal cells in the pelvic cavity [5]. Our patient presented with an extragenital AS with sarcomatous overgrowth. Sarcomatous overgrowth is characterized by the presence of a high-grade sarcomatous component in at least $25 \%$ of the tumour [42] and is associated with poor prognosis for both uterine and extra-uterine AS. In our review, patients with sarcomatous overgrowth showed a worse DFS than patients without overgrowth but log-rank $\mathrm{P}$ value between curves did not result completely significant (Fig. 6b).

In a recent retrospective study, patients with uterine AS showed a median OS of 161 months [43]. As reported by Murugasu [24], extra-genital AS is more aggressive than uterine AS, with AS recurring in $60 \%$ of extra-genital AS patients compared with $23 \%$ of uterine AS patients. In our review, 12/28 (42.9\%) patients with extra-genital AS relapsed. Haematogenous metastases have been found in 33\% of extra-genital AS patients compared to $2 \%$ of uterine AS patients. Death due to tumour occurred in $40 \%$ of extra-genital AS patients compared to $10 \%$ of uterine AS patients [24]. In our review, 8/28 (28.6\%) patients with extra-genital AS died of disease. The aggressiveness of extra-genital AS may be due to failure of the uterine myometrial wall as a barrier. Extra-genital AS is typically quite large at presentation and can easily spread to the peritoneum, to abdominal and pelvic organs, and to blood vessels. For this reason, it can easily cause bowel obstruction, and complete cytoreduction is not always easily achieved.

Surgical treatment, particularly complete surgical resection, represents the best course of action for AS. Patients with extra-uterine AS who received only surgery remained free of disease and never relapsed after treatment. Patients who underwent complete resection showed a better OS distribution than patients who 
underwent partial resection (Fig. 5e). Endometriosis, sarcomatous overgrowth, tumour size and age were not correlated with resection type. Because the number of patients who were not surgically treated was small, these results require further confirmation.

Moreover, survival seems to be not improved by bilateral salpingooophorectomy. Ovarian preservation for uterine or cervical AS may be feasible among premenopausal women. Indeed, women who underwent hysterectomy with salpingooophorectomy for uterine AS did not have longer survival than women who underwent only hysterectomy [43]. This finding was not tested in our review because we had a lot of missing data about postmenopausal status.

The OS of AS patients who received only surgery resulted more favourable than that of patients who received surgery with additional treatment or who did not undergo surgery (Fig. 6b). Probably, patients submitted to an exclusive surgery presented a completely resectable disease thanks to the biology of tumor or to the skills of surgeon. However, there were no differences in DFS between these three groups (Fig. 6b).

Different adjuvant treatments were delivered. Three patients received chemotherapy alone (anthracycline with an anti-angiogenesis agent [22]; bleomycin, etoposide and cisplatinum [28]; ifosfamide with cisplatin [31]), 3 received chemotherapy associated with radiotherapy (cytoxan +4000 rad of radiotherapy [7]; mesna, adriamycin, ifosfamide, carboplatinum and pelvic radiotherapy [24]; ifosfamide and cisplatin plus pelvic radiotherapy [25]), and two received only radiotherapy [5a-11].

Unfortunately, our review was limited by the low number of AS cases, by the lack of data and by short follow-up time reported in literature therefore statistical analysis was limited to Kaplan Meier curves comparison. Furthermore, our AS case was characterized by an extremely unusual aggressive clinical course that it seems to be not representative of AS common biological behavior. However, some indications may be suggested.

\section{Conclusion}

In summary, extra-uterine AS, particularly cases arising from extra-genital regions, is an extremely rare tumour. They are typically found in younger women than are uterine AS, and they usually involve huge, polylobate masses that can easily spread into surrounding organs and blood vessels. For extra-uterine AS, endometriosis represents a positive prognostic factor and sarcomatous overgrowth a negative prognostic factor; we could not asses the prognostic effect of heterologous sarcomatous elements for the scant number of cases included; however, independently of sarcomatous overgrowth, extra-uterine AS has a very poor prognosis. Although complete resection is not always feasible, surgery remains the mainstay treatment choice, whereas adjuvant therapy does not appear to be effective in prolonging OS. Surgical treatment of extra-uterine AS often requires an extensive surgery given the possible involving of multiple organs. Moreover, AS patients can be pluri-operated because of previous endometriosis treatment with consequent additional difficulties during surgery. Therefore, since surgery is the only treatment to have an impact on survival, patients should be centralized in qualified surgical oncological centres and operated by experienced surgeons to reduce morbidity and to achieve radical treatment. Nevertheless, centralization might allow the recovery of clinical data and histological samples allowing a revision and a definitive diagnosis. Considering that in the last forty years less than forty cases have been reported in the literature, a worldwide registry is urgently needed to collect data regarding these rare AS to standardize treatment and obtain reliable data on prognosis.

\section{Abbreviations \\ AS: Adenosarcoma; AWD: Alive with disease; Cl: Confidence interval; CT: Computed tomography scan; DFS: Disease-free survival; DOD: Died of disease; FOD: Free of disease; HR: Hazard ratio; HRT: Hormone replacement therapy; OS: Overall survival; SD: Standard deviation}

\section{Acknowledgements}

We are grateful to our Colleagues who answered our request to update follow-up data, particularly Dr. Mauro Cozzolino and Dr. Rhonda Yantiss.

\section{Funding}

The funding body had no role in the design of the study and collection, analysis, and interpretation of data and in writing the manuscript.

\section{Availability of data and materials}

Data collected and analyzed during this study are included in this review and are available from the corresponding author on reasonable request.

\section{Authors' contributions}

VDM conceived of the manuscript, performed operations, collected data, and wrote the manuscript. FT performed statistical analysis and wrote the manuscript. VM collected data and wrote the manuscript. RV performed pathological evaluation and wrote the manuscript. LA performed the operation and conceived of the manuscript. GBL conceived of and revised the manuscript. All authors read and approved the final manuscript.

\section{Ethics approval and consent to participate}

Written informed consent was not necessary because our patient provided standard written consent for the use of data, pictures and videos for teaching and research purposes at the time of laparotomy.

\section{Consent for publication}

Not applicable.

\section{Competing interests}

The authors declare that they have no competing interests. All authors deny any found, financial and personal relationships with other people or organizations/ companies that could inappropriately influence their work.

\section{Publisher's Note}

Springer Nature remains neutral with regard to jurisdictional claims in published maps and institutional affiliations. 


\section{Author details}

'Unit of Obstetrics and Gynecology, IRCCS- Azienda Unità Sanitaria Locale, Viale Risorgimento n 80, Reggio Emilia, Italy. ${ }^{2}$ Laboratory of Translational Research, Azienda Unità Sanitaria Locale, IRCCS, Reggio Emilia, Italy. ${ }^{3}$ Unit of Surgical Gynecol Oncology, Azienda Unità Sanitaria Locale, IRCCS, Reggio Emilia, Italy. ${ }^{4}$ Unit of Pathology, Azienda Unità Sanitaria Locale, IRCCS, Reggio Emilia, Italy. ${ }^{5}$ Unit of Obstetrics and Gynecology, University of Modena e Reggio Emilia, Reggio Emilia, Italy.

\section{Received: 2 March 2017 Accepted: 23 January 2018} Published online: 05 February 2018

\section{References}

1. Clement PB, Scully RE. Mullerian adenosarcoma of the uterus: a clinicopathologic analysis of 100 cases with a review of the literature. Hum Pathol. 1990;21:363-81

2. D'Angelo E, Prat J. Uterine sarcomas: a review. Gynecol Oncol. 2010;116:131-9.

3. Clement PB, Scully RE. Mullerian adenosarcoma of the uterus: a clinicopathologic analysis of ten cases of a distinctive type of mullerian mixed tumor. Cancer. 1974;34:1138-49.

4. Douglas GW, Kastin AJ, Huntington RW Jr. Carcinoma arising in a retroperitoneal muellerian cyst, with widespread metastasis during pregnancy. Am J Obstet Gynecol. 1965;91:210-6.

5. Clement PB, Scully RE. Extrauterine mesodermal (müllerian) adenosarcoma: a clinicopathologic analysis of five cases. Am J Clin Pathol. 1978;69:276-83.

6. Bard ES, Bard DS, Vargas-Cortes F. Extrauterine Müllerian adenosarcoma; a clinicopathologic report of a case with distant metastases and review of the literature. Gynecol Oncol. 1978;6:261-74.

7. Kao GF, Norris HJ. Benign and low grade variants of mixed mesodermal tumor (adenosarcoma) of the ovary and adnexal region. Cancer. 1978:42:1314-24.

8. Russell P, Slavutin L, Laverty CR, Cooper-Booth J. Extrauterine mesodermal (müllerian) adenosarcoma. A case report. Pathology. 1979;11:557-60.

9. Kerner $\mathrm{H}$, Lichtig C, Beck D. Extrauterine Mullerian adenosarcoma of the peritoneal mesothelium: a clinicopathologic and electron microscopic study. Obstet Gynecol. 1989;73:510.

10. Vara AR, Ruzics EP, Moussabeck O, Martin DC. Endometrioid adenosarcoma of the bladder arising from endometriosis. J Urol. 1990;143:813-5.

11. Roman LD, Mitchell MF, Tornos C, Glover A, Kavanagh JJ. Dedifferentiated Extrauterine Adenosarcoma responsive to chemotherapy. Gynecol Oncol. 1993;49:389-94.

12. de Jonge MJ, van Dam PA, Van Marck E, Prove A, van Oosterom AT. Primary extrauterine mullerian adenosarcoma of the peritoneum. Gynecol Oncol. 1995:57:126-30.

13. Benda JA, Veronezi-Gurwell A, Wilcox M, Buller R. An unusual extrauterine variant of adenosarcoma with multiple recurrences over 16 years. Gynecol Oncol. 1994:53:131-7.

14. Ostor AG, Nirenberg A, Ashdown ML, Murphy DJ. Extragenital adenosarcoma arising in the pouch of Douglas. Gynecol Oncol. 1994;53:373-5.

15. Inoue M, Fukuda H, Tanizawa O. Adenosarcomas originating from sites other than uterine endometrium. Int J Gynaecol Obstet. 1995;48:299-306.

16. Judson PL, Temple AM, Fowler WC Jr, Novothy DB, FunkHouser WK Jr. Vaginal adenosarcoma arising from endometriosis. Gynecol Oncol. 2000;76:123-5.

17. N'Senda $P$, Wendum D, Balladur $P$, Dahan H, Tubiana JM, Arrivè L Adenosarcoma arising in hepatic endometriosis. Eur Radiol. 2000;10:1287-9.

18. Kato N, Zhe J, Endoh Y, Motoyama T. Extrauterine Mullerian adenosarcoma of the peritoneum with an extensive rhabdomyosarcomatous element and a marked myxoid change. Pathol Int. 2000:50:347-51.

19. Yantiss RK, Clement PB, Young RH. Neoplastic and pre-neoplastic changes in gastrointestinal endometriosis: a study of 17 cases. Am J Surg Pathol. 2000;24:513-24

20. Visvalingam S, Jaworski R, Blumenthal N, Chan F. Primary peritoneal mesodermal adenosarcoma: report of a case and review of the literature. Gynecol Oncol. 2001;81:500-5.

21. Anderson J, Behbakht K, De Geest K, Bitterman P. Adenosarcoma in a patient with vaginal endometriosis. Obstet Gynecol. 2001;98:964-6.

22. Dincer AD, Timmins $P$, Pietrocola $D$, Fisher $H$, Ambros RA. Primary peritoneal mullerian adenosarcoma with sarcomatous overgrowth associated with endometriosis: a case report. Int J Gynecol Pathol. 2002;2:65-8.

23. Hines BJ, Porges RF, Mittal K, Muggia FM, Curtin JP. Use of Medroxyprogesterone acetate in the treatment of Mullerian adenosarcoma: a case report. Gynecol Oncol. 2002;85:192-5.
24. Murugasu A, Miller J, Proietto A, Millar E. Extragenital mullerian adenosarcoma with sarcomatous overgrowth arising in an endometriotic cyst in the pouch of Douglas. Int J Gynecol Cancer. 2003;13:371-5.

25. Liu L, Davidson S, Singh M. Mullerian adenosarcoma of vagina arising in persistent endometriosis: report of a case and review of the literature. Gynecol Oncol. 2003;90:486-90.

26. Raffaelli R, Piazzola E, Zanconato G, Fedele L. A rare case of extrauterine adenosarcoma arising in endometriosis of the rectovaginal septum. Fertil Steril. 2004:81:1142-4.

27. Toyoshima M, Akahira J, Moriya T, Hayakawa S, Yaegashi N. Primary vaginal adenosarcoma with sarcomatous overgrowth. Gynecol Oncol. 2004;95:759-61.

28. Kanngurn S, Somran J, Art-Ong C, Lamlertthon W, Porncharoenpong S. Primary peritoneal adenosarcoma with stromal overgrowth and fetal type cartilage: a case report and literature review. J Med Assoc Thail. 2005:88:849-54.

29. Chang HY, Chagchien CC, Chen HH, Lin H, Huang CC. Extrauterine mullerian adenosarcoma associated with endometriosis and rectal villotubular adenoma: report of a case and review of the literature. Int J Gynecol Cancer. 2005;15:361-5.

30. Milam MR, Atkinson JB, Currie JL. Adenosarcoma arising in inguinal endometriosis. Obstet Gynecol. 2006;108:753-5.

31. Huang GS, Arend RC, Sakaris A, Hebert TM, Goldberg GL. Extragenital adenosarcoma: a case report, review of the literature, and management discussion. Gynecol Oncol. 2009;115:472-5.

32. Han X, Leng J, Guo L, Xiang Y, Lang J. Vaginal adenosarcoma arising from refractory endometriosis: a case report. Aust N Z J Obstet Gynaecol. 2010;50:574-6.

33. Maeda M, Mabuchi S, Matsumoto Y, Hisamatsu T, Ohashi H, Kimura T. Activity of pegylated liposomal doxorubicin for extragenital mullerian adenosarcoma with sarcomatous overgrowth: a case report an a review of the literature. Eur J Gynaecol Oncol. 2011;32:542-6.

34. Patrelli TS, Sillini EM, Gizzo S, Beretta R, Franchi L, Thai E, et al. Extragenital Mullerian adenosarcoma with pouch of Douglas location. BMC Cancer. 2011;11:171

35. Clarke BA, Mulligan AM, Irving JA, McCluggage WG, Oliva E. Mullerian adenosarcomas with unusual growth patterns: staging issues. Int J Gynecol Pathol. 2011;30:340-7.

36. Karateke A, Kahramanoqlu I, Bilgiç R. Extragenital mullerian adenosarcoma in the pouch of douglas. Balkan Med J. 2014;31:100-4.

37. Yang C, Oh HK, Kim D. Mullerian adenosarcoma arising from rectal endometriosis. Ann Coloproctol. 2014;30:232-6.

38. Kar R, Verma SK, Papa D, Sylvia MT. Extrauterine adenosarcoma arising in omental endometriosis: rare site of occurrence of a rare tumor. Indian J Pathol Microbiol. 2014;57:640-1.

39. Pontrelli G, Cozzolino M, Stepniewska A, Bruni F, Pesci A, Ceccaroni M. Primary vaginal Adenosarcoma with Sarcomatous overgrowth arising in recurrent endometriosis: feasibility of laparoscopic treatment and review of the literature. J Minim Invasive Gynecol. 2016;23:833-8.

40. Krivak TC, Seidman JD, McBroom JW, MacKoul PJ, Aye LM, Rose GS. Uterine adenosarcoma with sarcomatous overgrowth versus uterine carcinosarcoma: comparison of treatment and survival. Gynecol Oncol. 2001;83:89-94.

41. Carroll A, Ramirez PT, Westin SN, Soliman PT, Munsell MF, Nick AM, et al. Uterine adenosarcoma: an analysis on management, outcomes, and risk factors for recurrence. Gynecol Oncol. 2014;135:455-61.

42. Clement PB. Müllerian adenosarcomas of the uterus with sarcomatous overgrowth. A clinicopathological analysis of 10 cases. Am J Surg Pathol. 1989;13:28-38.

43. Seagle BL, Kanis M, Strohl AE, Shahabi S. Survival of women with Mullerian adenosarcoma: a National Cancer Data Base study. Gynecol Oncol. 2016; S0090-8258:31485-8

44. Brooks SE, Zhan M, Cote T, Baquet CR. Surveillance, epidemiology, and end results analysis of 2677 cases of uterine sarcoma 1989-1999. Gynecol Oncol. 2004:93:204-8. 45

45. Nathenson MJ, Ravi V, Fleming N, Wang WL, Conley A. Uterine Adenosarcoma: a Review. Curr Oncol Rep. 2016;18:68.

46. Seagle BL, Falter KJ 2nd, Lee SJ, Frimer M, Samuelson R, Shahabi S. Mullerian adenosarcoma of the cervix: report of two large tumors with sarcomatous overgrowth or heterologous elements. Gynecol Oncol Case Rep. 2014;9:7-10.

47. Stern RC, Dash R, Bentley RC, Snyder MJ, Haney AF, Robboy SJ. Malignancy in endometriosis: frequency and comparison of ovarian and extraovarian types. Int J Gynecol Pathol. 2001;20:133-9. 
48. Zanetta GM, Webb MJ, Li H, Keeney GL. Hyperestrogenism: a relevant risk factor for the development of cancer from endometriosis. Gynecol Oncol. 2000;79:18-22

49. Mandato VD, Mastrofilippo V, Ciarlini G, Aguzzoli L, La Sala GB. Primary vaginal Adenosarcoma with Sarcomatous overgrowth arising in recurrent endometriosis: feasibility of laparoscopic treatment and review of the literature. J Minim Invasive Gynecol. 2016;S1553-4650:31287-0.

Submit your next manuscript to BioMed Central and we will help you at every step:

- We accept pre-submission inquiries

- Our selector tool helps you to find the most relevant journal

- We provide round the clock customer support

- Convenient online submission

- Thorough peer review

- Inclusion in PubMed and all major indexing services

- Maximum visibility for your research

Submit your manuscript at www.biomedcentral.com/submit
C Biomed Central 